2 Kovach JG, Dubin WR, Combs CJ. Psychotherapy training: residents' perceptions and experiences. Acad Psychiatry 2015; 39: 567-74.

3 Lanouette NM, Calabrese C, Sciolla AF, Bitner R, Mustata G, Haak J, et al. Do psychiatry residents identify as psychotherapists? A multisite survey. Ann Clin Psychiatry 2011; 23: 30-9.

4 Huhn M, Tardy M, Spineli LM, Kissling W, Forstl $\mathrm{H}$, Pitschel-Walz G, et al. Efficacy of pharmacotherapy and psychotherapy for adult psychiatric disorders: a systematic overview of meta-analyses. JAMA Psychiatry 2014; 71: 706-15.

5 McHugh RK, Whitton SW, Peckham AD, Welge JA, Otto MW. Patient preference for psychological vs. pharmacological treatment of psychiatric disorders: a meta-analytic review. J Clin Psychiatry 2013; 74: 595-602.
6 Friston K. The free-energy principle: a unified brain theory? Nat Rev Neurosci 2010; 11: 127-38.

7 Adams RA, Stephan KE, Brown HR, Frith CD, Friston KJ. The computational anatomy of psychosis. Front Psychiatry 2013; 4: 47.

8 Barsaglini A, Sartori G, Benetti S, Pettersson-Yeo W, Mechelli A. The effects of psychotherapy on brain function: a systematic and critical review. Prog Neurobiol 2014; 114: 1-14.

9 Gilbert CD, Li W. Top-down influences on visual processing. Nat Rev Neurosci 2013; 14: 350-63

10 Caroni $P$, Donato $F$, Muller D. Structural plasticity upon learning: regulation and functions. Nat Rev Neurosci 2012; 13: 478-90.

\title{
From asylum to psychiatric hospital in West Africa
}

\section{Dami Ajayi}

The Federal Neuropsychiatric Hospital Yaba, located in what has become the centre of Lagos mainland metropolis today, has changed names many times but its description as a facility remains the same, a place for respite for patients with mental illness.

Established 108 years ago, it was first called Yaba Lunatic Asylum. Yaba, then a suburb of the Nigeria's economic powerhouse Lagos, was a fitting location as it was customary of mental asylums to be located in far-to-reach places, just like correctional facilities. Prior to the establishment of asylums in West Africa, mentally ill patients were kept by their families in the custody of native doctors where they were contained and sometimes restrained. In 1888, there was a call for local asylums following the death of Adeola, a mentally ill person, who died after being refused admission at the general hospital. Before this time, 'lunatics' were sent as far as Sierra Leone for detention and treatment.

On 31 October 1907, 14 patients were admitted to an abandoned railway building which became the first male ward of the Yaba Lunatic Asylum. At this time, living conditions were almost subhuman, with crumbling buildings, lack of drugs and poor sanitation, but the patients thrived and despite these adversities lived into their sixties. After a brief stint of expatriate doctors in the mid-fifties, the facility (named Yaba Mental Hospital in 1951) was managed by Abraham Ordia, the first Nigerian psychiatric nurse, who commenced insulin coma therapy as well as phenothiazine injectables. Dr Crispin Curtis Adeniyi Jones, a medical doctor trained in Durham, was the first director of the hospital.

In spite of the exponential growth in the numbers of patients (100 in 1925, 200 in 1944, 448 in 1961), staff numbers were hardly sufficient, with an impossible staff/patient ratio. The lone doctor who manned the

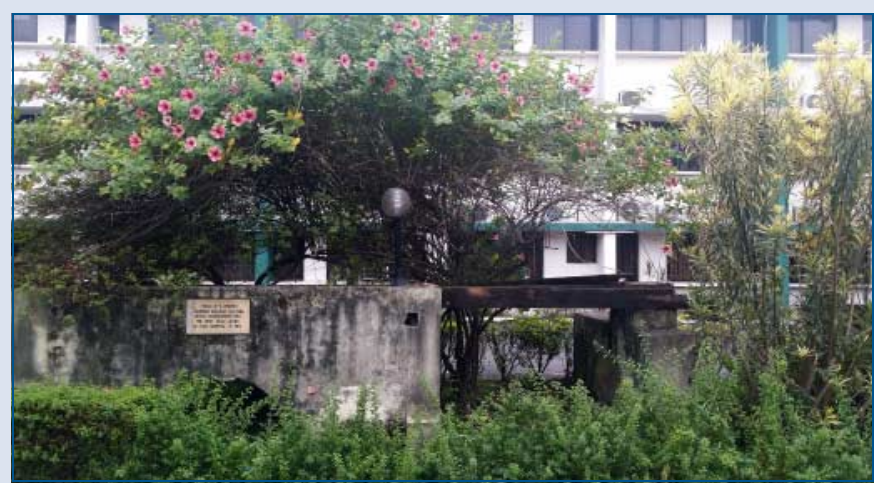

Entrance to the Yaba Hospital, Lagos, with remnants of the first hospital building on this site.

asylum was inadvertently overworked for he was also responsible for the lepers' colony nearby. It was not until 1961 that the hospital employed two psychiatrists: Dr A. Boroffka, a German, and Dr A. Marinho, the first Nigerian psychiatrist to work in the hospital. At this time, the hospital consisted of three buildings; two were for males and one for females. One of the male wards also housed criminal patients.

The hospital had a convalescent home in Oshodi, a few miles away, for patients with chronic illness who had no place to go. The expansive hospital compound also contained a football field, a vegetable garden and a poultry farm. Proceeds from the garden and farm were kept in a welfare fund which was used to entertain patients and staff at Christmas when a carol-singing party was organised. In 1967, four new wards and a modern cafeteria were built. One year later, Dr Bertha Johnson, a medical officer employed by the hospital, returned from her postgraduate training in psychiatry. She rose in rank to become the hospital's medical director and it was during her tenure that the hospital was modernised to appreciable standards.

Today, the hospital boasts 535 in-patient beds, a modern kitchen/dining hall complex, an administrative block, an out-patient department, a psychology department, and assumes the status of a fully-fledged psychiatric hospital. Wards have been named after various pioneers who worked in the hospital and there is a social centre opened to members of the general public for relaxation and recreational activities. At the hospital's entrance, there is a relic of what was the first ward of the hospital, a disused railway building preserved to remind us of how this space transitioned from an asylum to a hospital (see photo). 